\title{
REVIEW
}

Open Access

\section{Open necrosectomy is feasible as a last resort in selected cases with infected pancreatic necrosis: a case series and systematic literature review}

Lucia llaria Sgaramella', Angela Gurrado ${ }^{1}$, Alessandro Pasculli ${ }^{1}$, Francesco Paolo Prete ${ }^{1}$, Fausto Catena ${ }^{2}$ and Mario Testini $i^{*}$ (1)

\begin{abstract}
Background: Acute pancreatitis is a common inflammatory pancreatic disorder, often caused by gallstone disease and frequently requiring hospitalization.

In $80 \%$ of cases, a rapid and favourable outcome is described, while a necrosis of pancreatic parenchyma or extrapancreatic tissues is reported in $10-20 \%$ of patients. The onset of pancreatic necrosis determines a significant increase of early organ failure rate and death that has higher incidence if infection of pancreatic necrosis (IPN) or extra-pancreatic collections occur.

IPN always requires an invasive intervention, and, in the last decade, the advent of minimally invasive techniques has gradually replaced the employment of the open traditional approach.

We report a series of three severe cases of IPN managed with primary open necrosectomy (ON) and a systematic review of the literature, in order to understand if emergency surgery still has a role in the current clinical practice.

Methods: From January 2010 to January 2020, 3 cases of IPN were treated in our Academic Department of General and Emergency Surgery. We performed a PubMed MEDLINE search on the ON of IPN, selecting 20 from 654 articles for review.

Results: The 3 cases were male patients with a mean age of 61.3 years. All patients referred to our service complaining an evolving severe clinical condition evocating a sepsis due to IPN. CT scan was the main diagnostic tool. Patients were initially conservatively managed. In consideration of clinical worsening conditions, and at the failure of conservative and minimal invasive treatment, they were, finally, managed with emergency ON. Patients reported no complications nor procedure-related sequelae in the follow-up period.
\end{abstract}

Conclusion: The ON is confirmed to be the last resort, useful in selected severe cases, with a defined timing and in case of proven non-feasibility and no advantage of other minimally invasive approaches.

Keywords: Infected pancreatic necrosis, Pancreatic collection, Walled-off necrosis, Open surgical necrosectomy, Pancreatic abscess

\footnotetext{
* Correspondence: mario.testini@uniba.it

"Unit of General Surgery "V. Bonomo", Department of Biomedical Sciences and Human Oncology, University of Bari "A. Moro", Polyclinic of Bari, Piazza Giulio Cesare, 11, 70124 Bari, Italy

Full list of author information is available at the end of the article
}

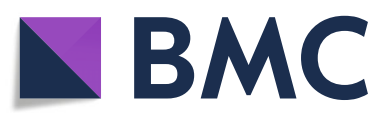

( ) The Author(s). 2020 Open Access This article is licensed under a Creative Commons Attribution 4.0 International License, which permits use, sharing, adaptation, distribution and reproduction in any medium or format, as long as you give appropriate credit to the original author(s) and the source, provide a link to the Creative Commons licence, and indicate if changes were made. The images or other third party material in this article are included in the article's Creative Commons licence, unless indicated otherwise in a credit line to the material. If material is not included in the article's Creative Commons licence and your intended use is not permitted by statutory regulation or exceeds the permitted use, you will need to obtain permission directly from the copyright holder. To view a copy of this licence, visit http://creativecommons.org/licenses/by/4.0/. The Creative Commons Public Domain Dedication waiver (http://creativecommons.org/publicdomain/zero/1.0/) applies to the data made available in this article, unless otherwise stated in a credit line to the data. 


\section{Background}

Acute pancreatitis (AP) is an inflammatory pancreatic disorder and the most common gastro-intestinal disease requiring hospitalization [1]. The incidence trend varies between 4.9 and 73.4 cases per 100,000 worldwide, and an increasing rate has been reported [2-6].

Gallstones are the leading cause of AP, accounting for $35-40 \%$ of cases, characterized by abdominal pain and elevation of pancreatic enzymes in the blood. In most of cases (80\% of patients), a rapid and favourable outcome is described. However, approximately $10-20 \%$ [3] of patients develop necrosis of pancreatic parenchyma or extra-pancreatic tissues determining a significant increase of early organ failure rate (38\%) and death (15\%) $[7,8]$. Patients with severe complications of acute necrotic pancreatitis (ANP) or peripancreatic fluid collection are currently treated with a primary conservative approach, and interventions are avoided or postponed until the necrosis becomes walled-off (WON) and liquefied. The major cause of death and multiorgan failure in case of complicated pancreatitis is the infection of pancreatic necrosis (infected pancreatic necrosis IPN) or extra-pancreatic collections that develop in approximately $30 \%$ of patients and lead to an increase of mortality to approximately 39\% [9-14]. In such cases (about one third), an invasive intervention becomes mandatory to avoid a life-threatening evolution $[9,15]$.

The traditional approach to the treatment of IPN had historically been open necrosectomy $(\mathrm{ON})$ with the complete removal of the infected tissue. Nevertheless, due to the still high rates of complications and death characterizing the $\mathrm{ON}$, in the last decade, it has been gradually replaced by minimally invasive procedures that seem to reduce the incidence of postoperative new-onset organ failure compared with the open procedures [12, 13, 16-18]. Less invasive procedures, indeed, have been successfully proposed and tested, such as percutaneous drainage (PD), endoscopic transgastric necrosectomy (ETN), or video-assisted retroperitoneal debridement (VARD) [19, 20]. Recent evidence suggests that the surgical "step-up approach", including PD, followed, if necessary, by minimally invasive necrosectomy, could be preferred to open surgery and be considered as the standard treatment for IPN with lower rates of postoperative adverse events (40\%) and long-term morbidity [14]. Only few randomized controlled trials (RCT) comparing the step-up approach with ON have been performed, and the high variability of surgical procedures and materials proposed in the step-up procedures justifies the difficulty in the technique standardization [21-24]. Therefore, ON with repeated laparotomies is considered the last choice, whereas other therapeutic options have failed.

The aim of this study was to report our institution experience over the last 10 years and to review the recent literature on the open surgical management of IPN in order to understand if traditional surgical necrosectomy still has a role in the current clinical practice.

\section{Main text \\ Cases presentation}

From 2010 to 2020, 3 cases of IPN have been treated in our Academic Department of General and Emergency Surgery. We retrospectively reviewed clinical presentation, diagnosis, treatment, and follow-up.

\section{Case 1}

A 65-year-old man was admitted to our Department of General Surgery after 15 days from the onset of severe acute gallstone pancreatitis medically treated in another hospital. His past medical history revealed essential hypertension under treatment and splenectomy for trauma. A CT scan performed 4days prior to our hospitalization revealed multiple pancreatic and peripancreatic necrotic fluid collections involving the retroduodenal space and the splenic lodge. At the admission, the patient was febrile $\left(38.3^{\circ} \mathrm{C} / 100,94 \mathrm{~F}\right)$ with other normal vital signs. He referred left upper quadrant abdominal pain, abdominal distension, anorexia, and loss of weight accompanied with constipation. At physical examination, the abdomen was generally distended but not tender, with a large palpable mass in the left upper quadrant. Routine biochemistry showed leucocytosis $\left(11.27 \times 10^{3} / \mathrm{uL}\right)$ and an increase in inflammatory markers (C-reactive protein: CRP $102.0 \mathrm{mg} / \mathrm{L}$ ). A CT scan of the abdomen and pelvis revealed a heterogeneous $85 \times 68 \times$ 60-mm pancreatic necrotic collection (Fig. 1a, b) with extension to the retro-duodenal space, to the mesenteric root, and to the splenic lodge, while an magnetic resonance cholangiopancreatography (MRCP) confirmed the presence of biliary endoluminal sludge in the gallbladder and terminal bile duct (BD) causing obstruction and proximal distension (10-mm diameter).

The patient was conservatively treated with fluid resuscitation, antibiotics, and supportive treatment as well as nutritional support. Moreover, an endoscopic retrograde cholangiopancreatography (ERCP) with endoscopic sphincterotomy and clearing of BD was performed. Because of the worsening of clinical condition, a percutaneous US-guided drainage was attempted, failing in relation to the its heterogeneous and sepimented content with prevalence of solid necrotic tissue. With the occurrence of clinical worsening and hemodynamic instability, an emergency open surgical debridement was performed 35 days after ANP clinical onset. An extended adhesiolysis was performed, followed by cholecystectomy, opening of gastrocolic ligament with marsupialisation of the collection wall and $\mathrm{ON}$ with debridement of necrotic content. Finally, drainages were left in place. During the operation, the fluid component was aspirated and sent to lab for culture and sensitivity. Infection of 


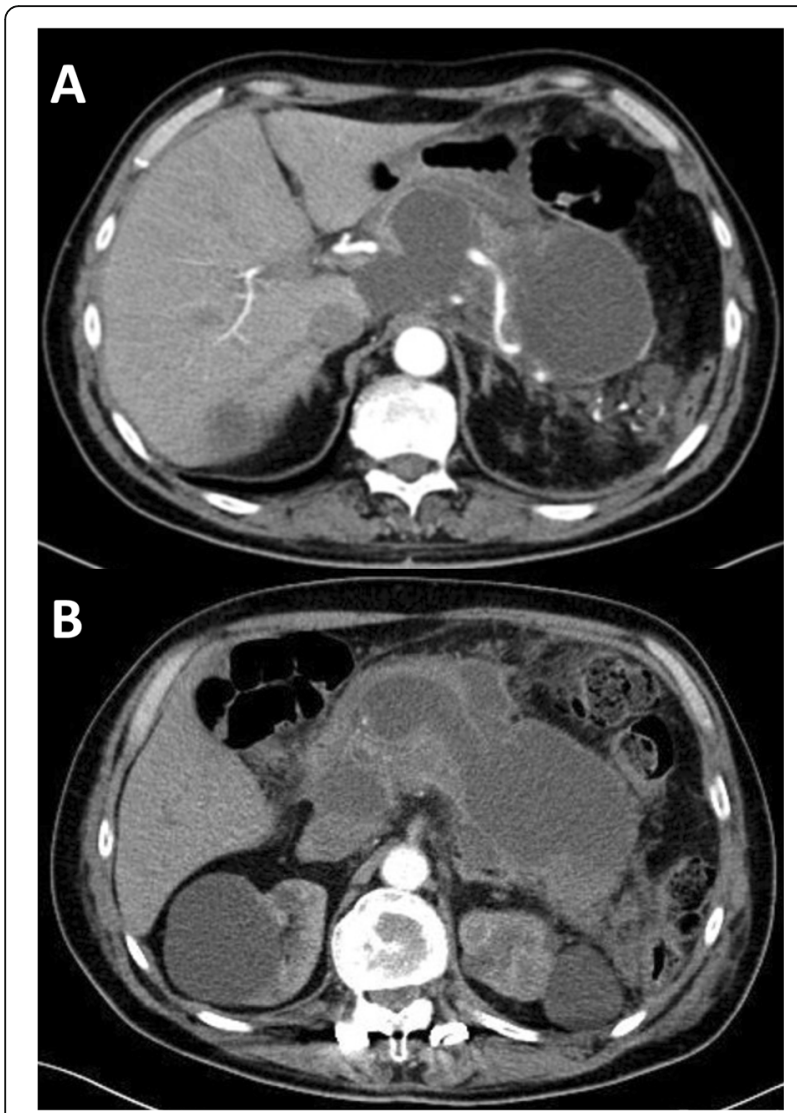

Fig. 1 Case 1: Preoperative CT scan. $\mathbf{a}, \mathbf{b} C T$ scan of the abdomen and pelvis revealing a heterogeneous $85 \times 68 \times 60-\mathrm{mm}$ pancreatic necrotic collection

WON, indeed, was confirmed by bacterial culture positive to Enterococcus Faecium.

The post-operative time was uneventful. Drainages were removed on the 15th post-operative day and after 17 days, the patient was discharged. $\mathrm{He}$ has been followed up for a post-operative time of 8 months during which no sequelae were identified, and a follow-up CT scan showed that the infected WON had resolved with diminished inflammatory changes in the pre-pancreatic region.

\section{Case 2}

A 60-year-old man referred in emergency to our Academic Unit of General Surgery with a severe clinical condition evocating a sepsis due to IPN. At the admission, he was tachycardic (heart rate 120 beats/min) and febrile $\left(38.7^{\circ} \mathrm{C} / 101.66 \mathrm{~F}\right)$, presenting abdominal pain and distension, general malaise, and anorexia. At physical examination, the abdomen was distended, and a large mass was palpable. He had been submitted to cholecystectomy 1 month before admission, and he had developed a severe post-operative ANP. Routine biochemistry evidenced an increase in inflammatory markers (PCR 171.0 $\mathrm{mg} / \mathrm{L})$ and leucocytosis $\left(14.42 \times 10^{3} / \mathrm{uL}\right)$, and CT scan and MRCP showed a heterogeneous and sepimented 23 $\times 15-\mathrm{cm}$ low-density lesion, suggestive for infected WON with extension to the retro-duodenal space, the mesenteric root, and the splenic lodge surrounding splenic vessels (Fig. 2a, b). The collection also caused compression of the liver and hepatic hilum, stomach, and intestinal obstruction. He was managed with antibiotics therapy and fluid resuscitation. Nevertheless, the patient developed severe sepsis (leucocytosis $18.96 \times$ $10^{3} / \mathrm{uL}$; presepsin $538 \mathrm{pg} / \mathrm{mL}$ ) evolving into shock, and the minimally invasive approach was waived in favor of emergency surgical debridement. On the 30th day after the onset of ANP, an extended adhesiolisis was performed with opening of gastrocolic ligament and of the WON, and the IPN was drained with an ON, necrotic debridement, and drainage placement (Fig. 3a, b).

The post-operative time was uneventful. Drainages were removed on the 13th postoperative day, and the patient was discharged on the 15th day.

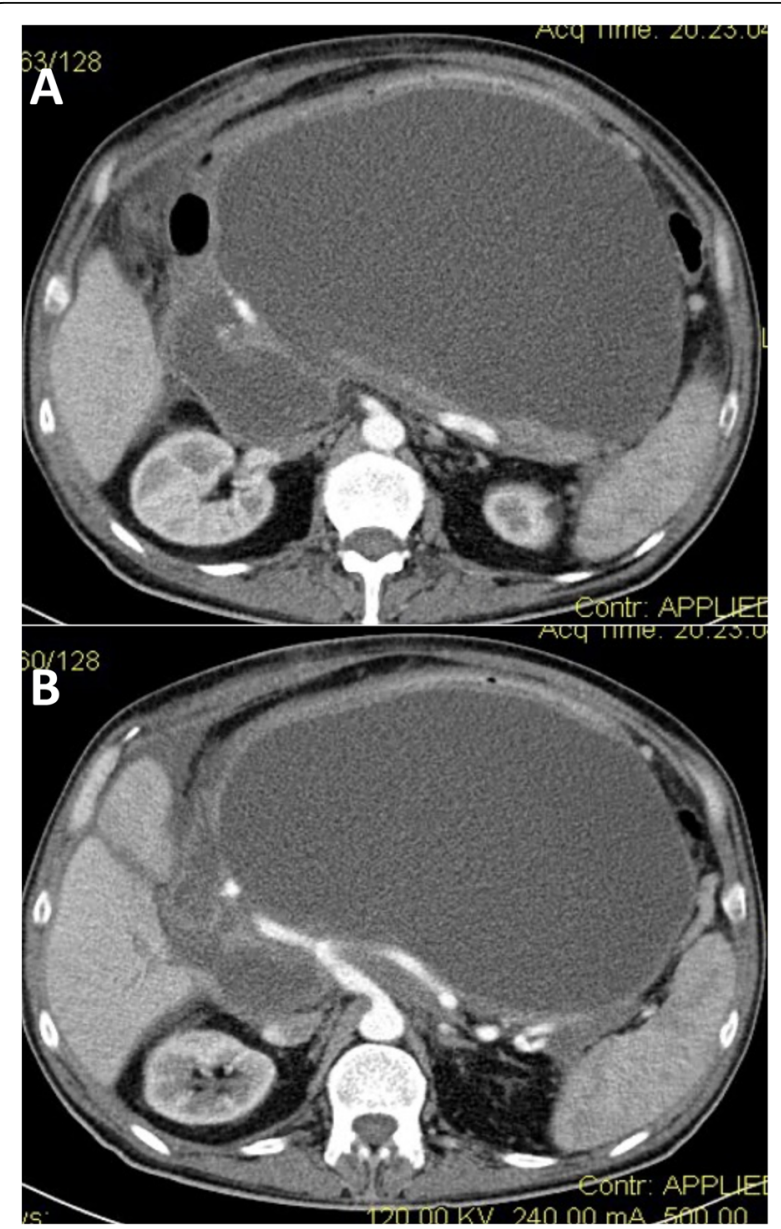

Fig. 2 Case 2: Preoperative CT scan. a, b CT scan showing a heterogeneous and sepimented $23 \times 15-\mathrm{cm}$ low-density lesion suggestive for infected pancreatic necrosis 


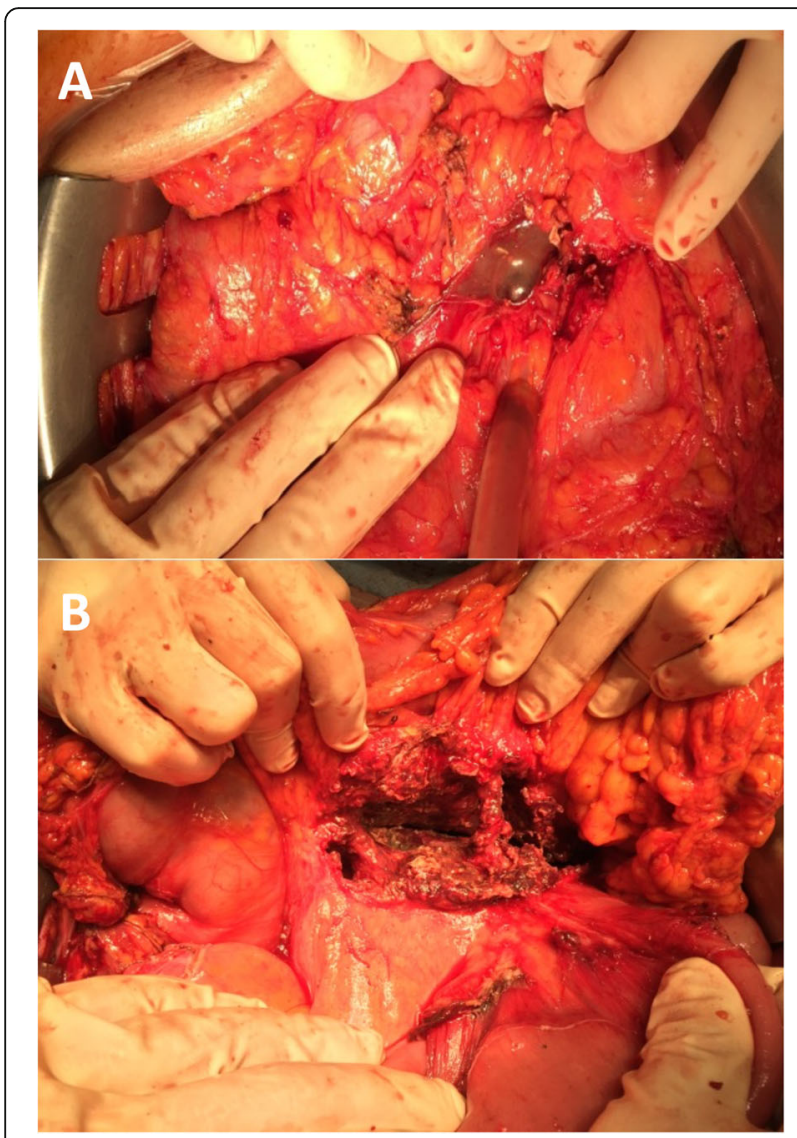

Fig. 3 Case 2: Intraoperative images. a, b Intraoperative imaging of open necrosectomy

\section{Case 3}

A 59-year-old male was admitted from the emergency room for severe continuous epigastric pain that had originated a few hours previously at home. He had been discharged the day before after recovering from an episode of acute cholecystitis managed with conservative treatment and having been scheduled for elective cholecystectomy. He underwent an emergency CT scan confirming the gallstone disease and showing a new finding of 6-mm stone impaction at the distal end of the common BD. Blood tests were unremarkable. After 24h, blood tests showed evidence of a marked elevation of serum amylase (975 U/L) and lipase (4395 U/L) without significant jaundice, and a new CT scan, performed $48 \mathrm{~h}$ after the previous one, showed the onset of ANP, with duodenal swelling. A mandatory oesophagogastroduodenoscopy (OGD) was then performed revealing patches of gastric antrum and duodenal necrosis. He was kept on conservative management with parenteral nutrition for more than 10 days before another OGD that showed a stabilization of the severe but not perforated duodenal disease. On hospital day 25, he developed pyrexia up to $38.5^{\circ} \mathrm{C}(101.3 \mathrm{~F})$ and showed high white cell count $\left(21.06 \times 10^{3} / \mathrm{uL}\right.$ [normal range 3.70-9.70]). CT scan and MRCP showed acute gallstone cholecystitis and signs suggestive for IPN (Fig. 4a-d). Fluid collection in the right retroperitoneal and perihepatic space and severe oedema of peri-pancreatic adipose tissue were also documented, with abdominal and pelvic effusion.

Due to the compromised duodenal status, an ERCP was withheld, and we decided to perform a hazardous surgical exploration with a program of cholecystectomy and necrotic debridement in consideration of the sudden clinical worsening. After 1 month from the clinical onset of ANP, an open extensive adhesiolisis, cholecystectomy, and necrosectomy were performed, along with gastroentero anastomosis to divert the alimentary tract away from the damaged duodenum; both the hepatic and the common BD appeared weakened and under dense adhesions, and it was too risky to position a biliary drainage, nor it was possible to consider a high-morbidity alternative as an emergency pancreaticoduodenectomy [25, 26]. The IPN was drained, and drains were left in place. On the 10th postoperative day, anaemia ( $\mathrm{Hg} \mathrm{7.8)}$ with a CT evidence of self-limiting bleeding from epiploic vessels managed with embolization occurred. Moreover, a wellcontrolled and drained duodenal lateral fistula from the posterior wall of the weakened duodenum was evident, and it was initially conservatively managed, keeping the drain in place. Two months after the admission, the patient was discharged in fairly good clinical conditions, on a diet with oral intake. After 1 month of follow-up, an external internal drainage was positioned in order to approach the persistent duodenal fistula. The patient died after 3 months for a brain stroke.

\section{Review of literature}

A systematic review was performed by searching in PubMed/MEDLINE from 2010 to 2020, using the following keywords: "infected walled off pancreatic necrosis" OR "open necrosectomy AND necrotizing pancreatitis" OR "Pancreatitis AND infected AND necrosis AND surgery".

\section{Inclusion and exclusion criteria}

All studies meeting the inclusion criteria were considered for the review: cohorts of almost 15 patients with necrotizing pancreatitis undergoing primary $\mathrm{ON}$ for suspected or confirmed IPN and in which primary outcomes were reported (percentage of infected, open surgery success rate, mortality, and complications). Comparative studies, concerning the employment of different techniques with a total cohort of patient higher than 15 , were considered in case of almost 10 patients with IPN managed with primary ON.

Contrariwise, the following were excluded: nonEnglish papers, studies with study cohorts of less than 15 patients, studies including patients with chronic 


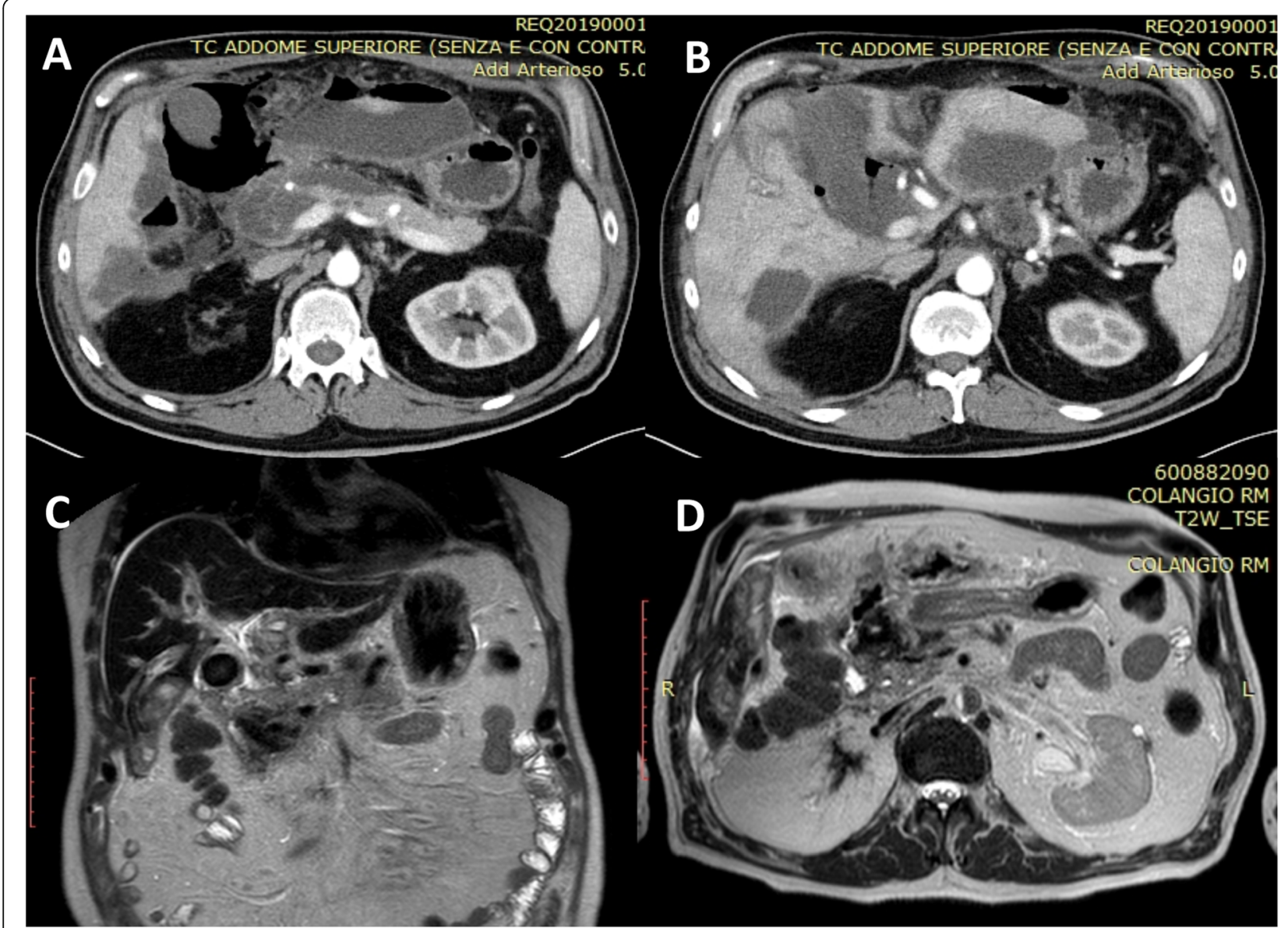

Fig. 4 Case 3: Preoperative CT scan and MRCP. CT scan $(\mathbf{a}, \mathbf{b})$ and MRCP (c, d) showing acute gallstone cholecystitis and signs suggestive for infected pancreatic necrosis

pancreatitis or with results for acute pancreatitis not reported separately, studies including patients classified as pseudocysts or pancreatic abscess as defined by the 1992 Atlanta classification, studies including sterile pancreatic necrosis with results of IPN not reported separately, or studies concerning uncomplicated sterile necrotic pancreatitis.

\section{Study selection}

The search returned 654 papers after removing duplicates. The study selection flowchart is shown in Fig. 5.

Six hundred and eighteen publications were excluded after reviewing title, abstract, and full text for the following reasons: non-English papers $(N=61)$; not relevant or off-topic $(N=236)$; studies with cohorts of less than 15 patients $(N=95)$ or with less than 10 patients managed with primary open surgery for IPN $(N=2)$; cohorts including only endoscopic management $(N=28)$ or only percutaneous management $(N=15)$; cohorts of only step-up approaches $(N=12)$, including any additional mini-invasive management $(N=16)$ or other invasive approaches $(N=12)$; cohorts that did not report essential outcomes $(N=4)$; and cohorts excluded because of non-original patient data (reviews or solely descriptive publications, $N=143$; complications, $N=1$ ). Furthermore, nine studies were also excluded because patient's data were unclear or incomplete $(N=8)$ or because of long-term follow-up studies $(N=1)$.

Finally, a total of 20 studies were included in the systematic review [12, 14, 27-44].

\section{Study characteristics}

This systematic review analyzes the results of patients submitted to primary ON for IPN. Studies and patients' characteristics are summarized in Table 1.

The vast majority of the analyzed studies $(N=18$; $90 \%)$ were retrospective with the exception of 1 multicentre randomized study and 1 prospective study.

The pooled data of this review is 879 patients submitted to open surgery for suspected or preoperatively confirmed IPN. The mean number of patients involved per study is 43.9, ranging from 15 to 120 ; the majority of patients were men while the reported age ranges from 16 to 88 . 


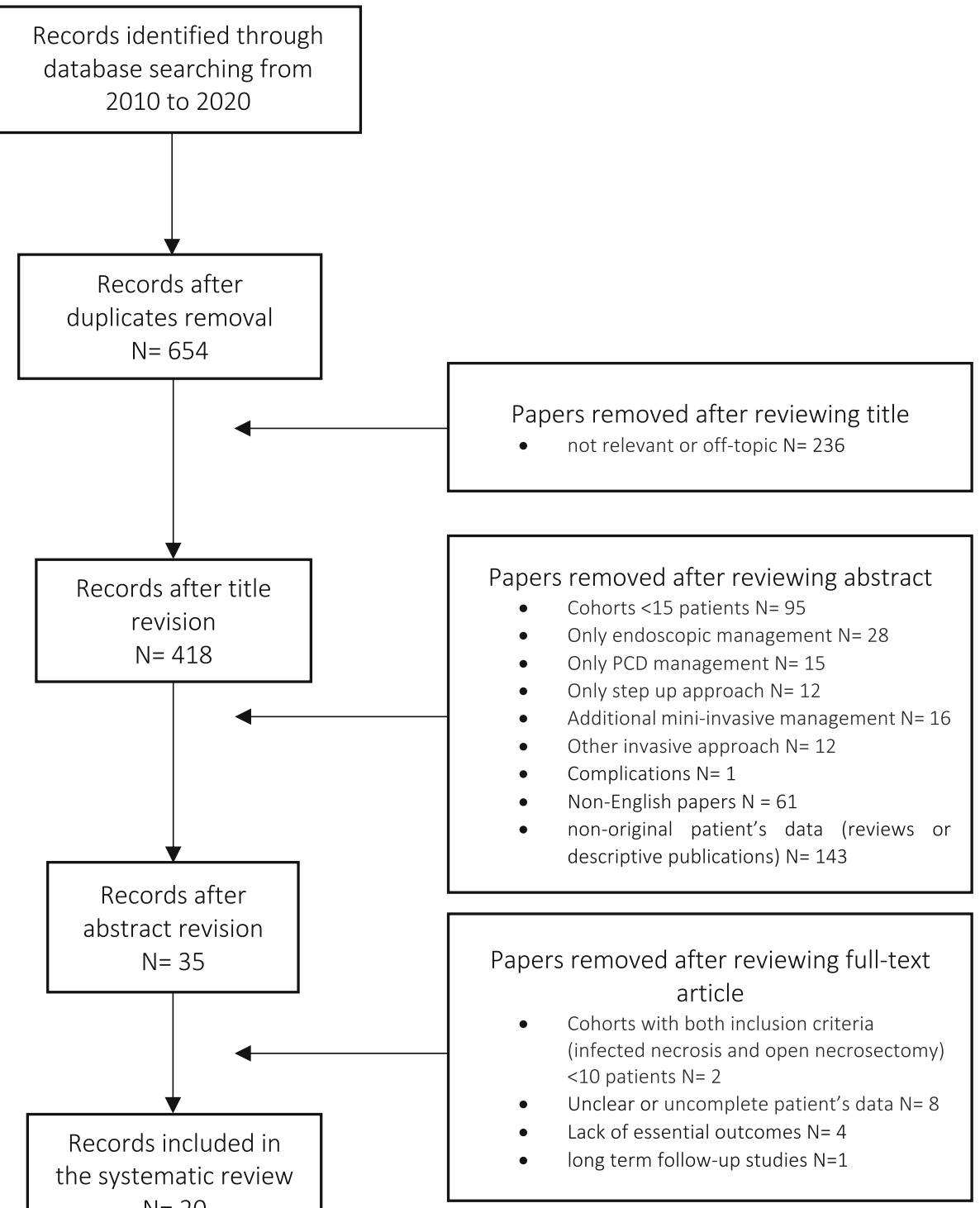

Fig. 5 Study selection flowchart

Not all studies are complete in providing all predictive severity scores, preoperative clinical presentation, and details. Seventeen studies, indeed, have indicated disease aetiology, whose majority was alcoholic or biliary. The CTI score (CT severity index) is reported in fourteen studies with a value usually higher than 7; APACHE II score (Acute Physiologic and Chronic Health Evaluation II) is present in 12 studies with a value greater than 9, while details on preoperative organ failure and intensive care unit (ICU) admission are present in sixteen and six studies, respectively. Nine studies underline preoperative American Society of Anaesthesiologists (ASA) score and/or pre-existing comorbidities, with cardiovascular disease being the most commonly present followed by acute or chronic renal insufficiency and pulmonary dysfunction. Details on operative management and post-operative course are reported in Table 2. Nine studies have highlighted details on collection characteristics describing how a large part of patients has an extension of necrotic tissue involving up to $50 \%$ of parenchyma at the time of surgery.

As in the inclusion criteria, all studies include patients submitted to primary ON for suspected or confirmed IPN but, in the same studies, also organ failure, prolonged pain, bleeding, persisting unwellness, and/or gastric outlet obstruction are considered as indications for open surgery. The reported time until necrosectomy from admission in days includes great excursions and ranges from 0 to 155 days. 


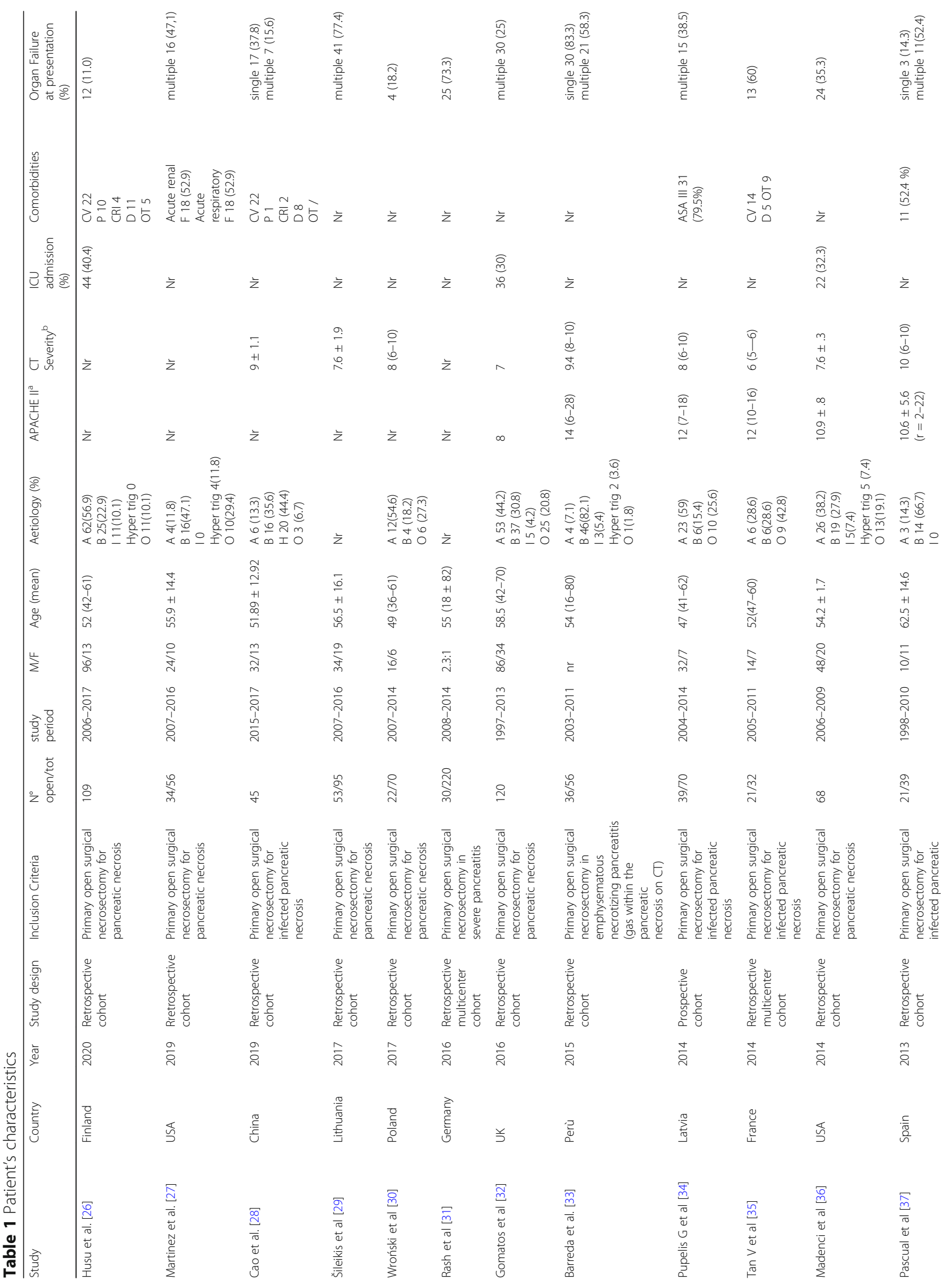


Sgaramella et al. World Journal of Emergency Surgery

(2020) $15: 44$

Page 8 of 14

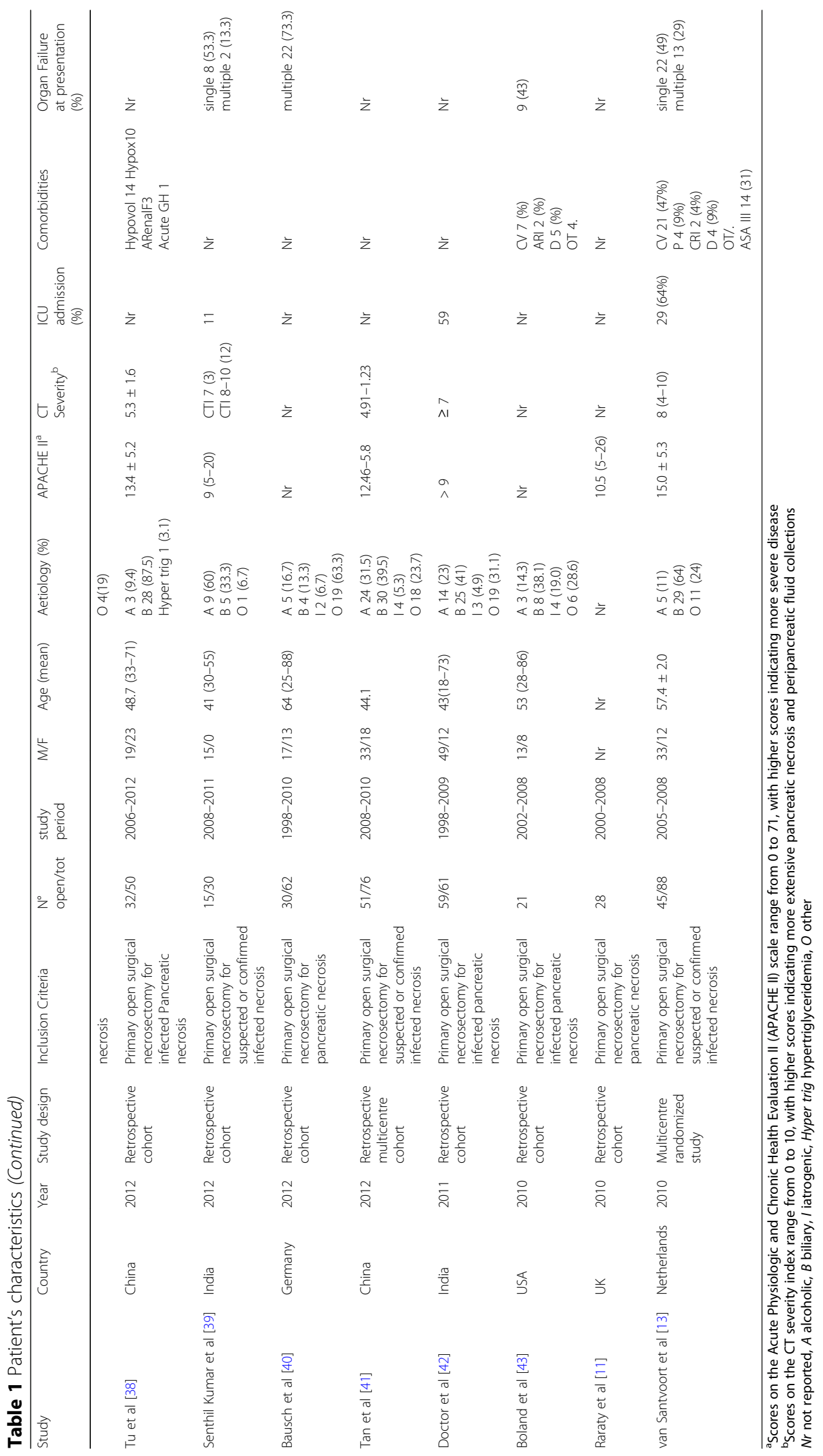


Sgaramella et al. World Journal of Emergency Surgery

(2020) $15: 44$

Page 9 of 14

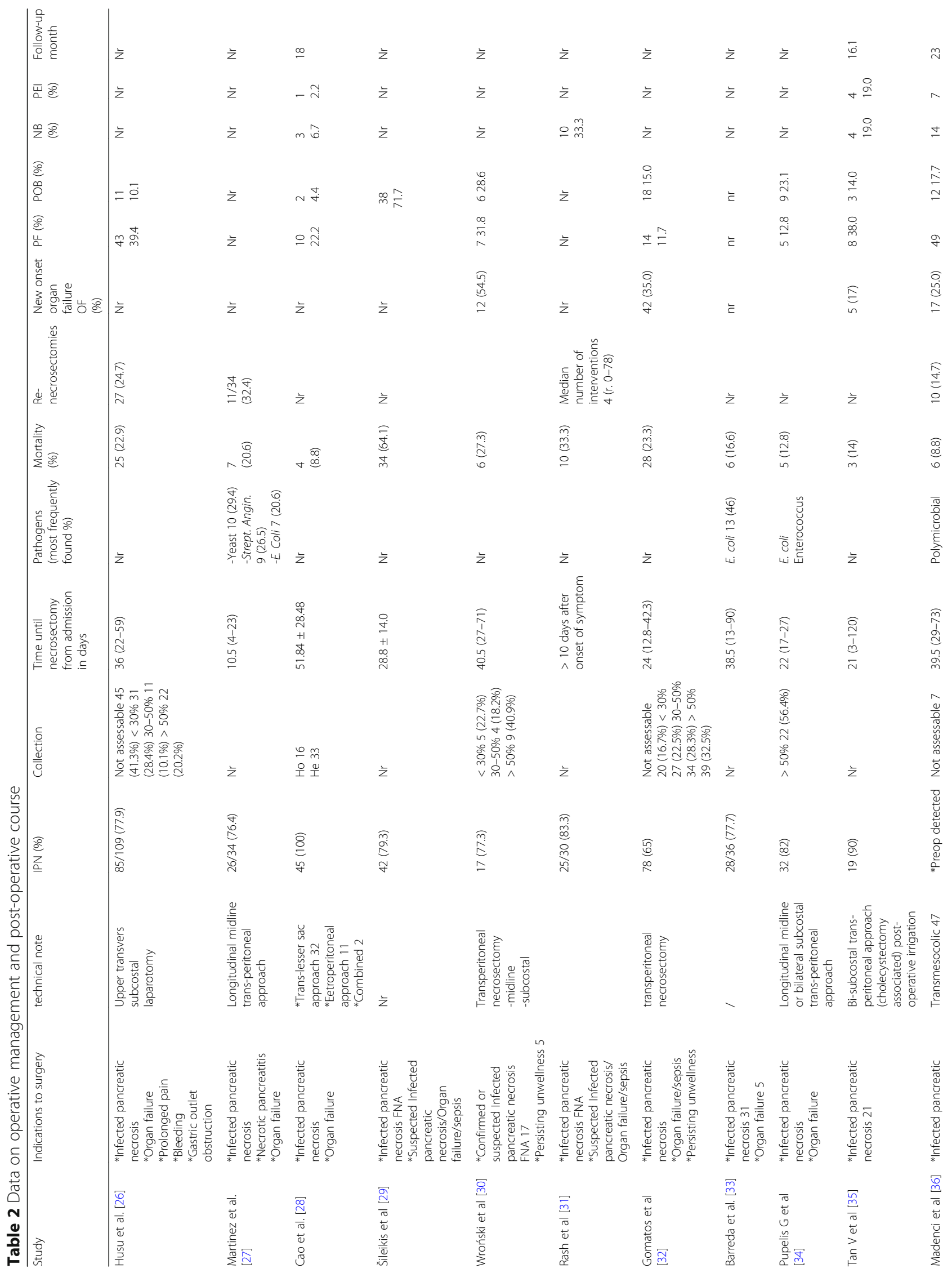


Sgaramella et al. World Journal of Emergency Surgery

(2020) 15:44

Page 10 of 14

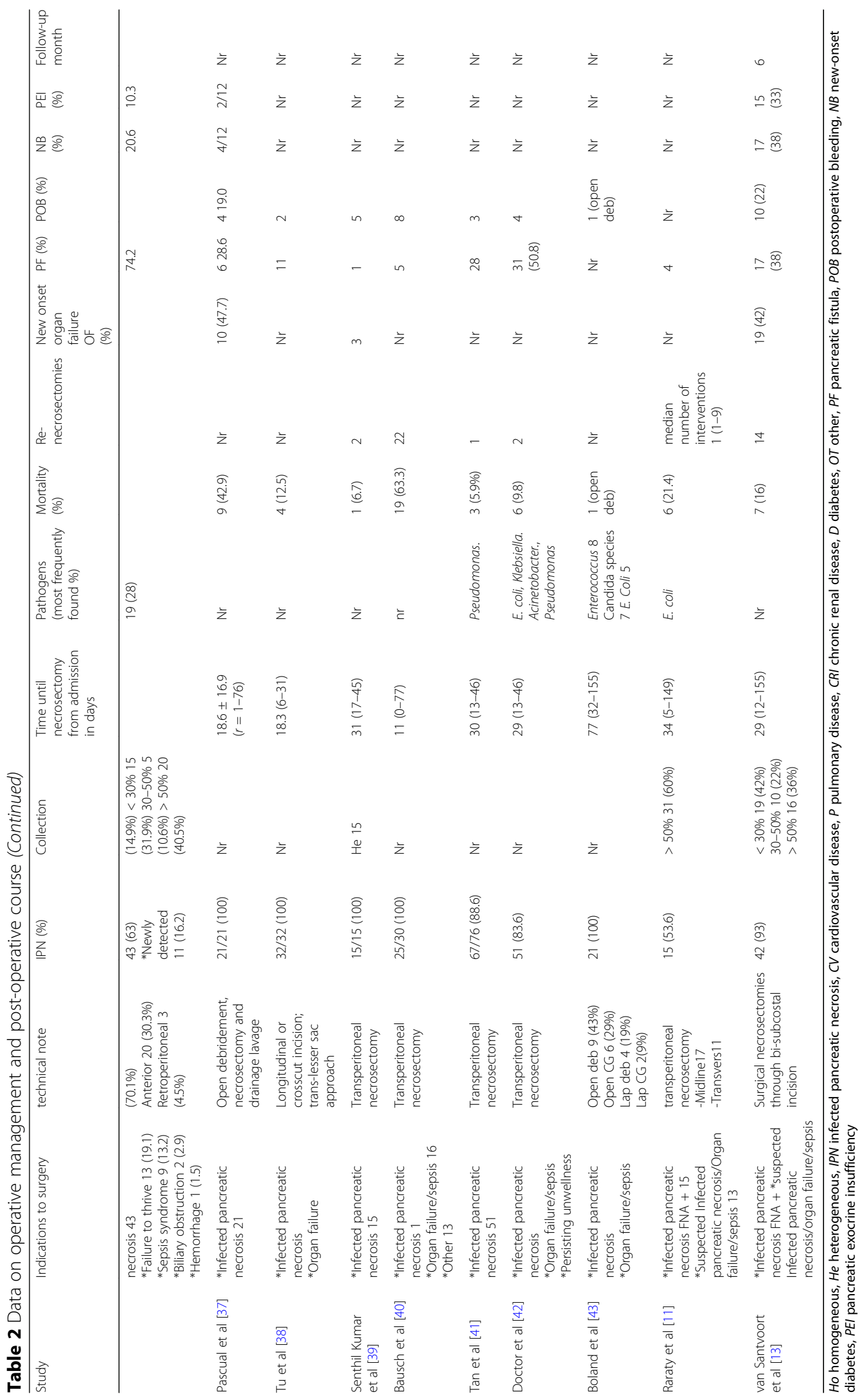


Most studies describe results on ON with the use of longitudinal midline or bilateral subcostal trans-peritoneal approach. Only three studies reporting the use of different techniques, of which at least one is the traditional open approach, have been added to the review. Nine out of twenty studies involved in the review report data on the necessity of re-necrosectomy. On a total of 879 patients, a positive bacteriological culture was described in 740 , confirming the preoperative suspicion of IPN in $84.2 \%$ cases. The most frequently pathogens found are E. coli, Klebsiella, Acinetobacter, Pseudomonas, Enterococcus, and Candida species.

Mortality rate was reported in all studies with a high variability ranging from 6.7 to 64.1 , while not all studies are complete in describing acute or chronic postoperative complications. Indeed, seven studies added information on new onset of post-operative organ failure with 108 patients (34.6\%) on 312 of the reporting studies developing new organ failure. Acute post-operative complications have been pointed out in seventeen studies with $49.4 \%$ of patients (385 on 779) developing pancreatic fistula or post-operative bleeding. Chronic complications are debated in six studies showing, on a pool data of 230 patients, the new onset of diabetes in 52 patients (22.6\%) and pancreatic exocrine insufficiency in 29 (12.6\%).

\section{Discussion}

The revised version of the Atlanta Classification in 2012 has replaced the nomenclatures of 1992 for various types of acute pancreatitis complications, such as pancreatic abscess, initially defined as a "localised collection of purulent material without significant necrotic material." It has allowed to make a clear distinction in different pancreatic collections [45]. The collections with only fluid content usually occur from interstitial oedematous pancreatitis and are defined as acute peripancreatic fluid collection if these occurs during the first weeks from the arising of the pancreatitis, or pancreatic pseudocyst as a delayed (usually $>4$ weeks) complication. On the other hand, collections arising from ANP usually contain a solid and fluid component. These are defined as acute necrotic collection occurring in the early phase of pancreatitis and before demarcation, or WON, which represents a heterogeneous spectrum of solid and liquid collections (necrotic debris and fluid) surrounded by a radiologically identifiable capsule (which rarely develops before 4 weeks from onset of pancreatitis) [3].

Infection of such pancreatic fluid or necrotic collection is an unusual circumstance reported in literature, occurring in approximately $30 \%$ of patients with necrotizing pancreatitis but is related to a high mortality rate (20\%) [8-14]. The common clinical manifestations of IPN are persistent fever, abdominal discomfort, or back pain accompanied to early satiety, anorexia, weight loss, abdominal distention, vomiting, or worsening reflux due to partial or complete gastric or duodenal outlet obstruction $[46,47]$. The presence of a systemic inflammatory response syndrome, with modification of inflammatory markers (elevation of C-reactive protein, progressive leucocytosis or positive blood cultures) and the onset of clinical deterioration in a stable patient on adequate support, with new or prolonged organ failure, are suggestive for IPN in $80 \%$ of cases [46, 47]. Jaundice may also occur secondary to biliary obstruction while symptoms related to hemorrhage into WON and gastroduodenal and/or splenic arterial erosions are more critic with hemodynamic instability.

Imaging signs such as gas in peripancreatic collections with or without a rapid accumulation on serial imaging are accurate predictors of IPN in the majority of patients [48-50]. The diagnosis of IPN, indeed, can be suspected by the patient's clinical course, by the presence of gas within the heterogeneous or homogeneous collection seen on contrast enhancement CT or when percutaneous, image-guided, fine-needle aspiration (FNA) is positive for bacteria and/or fungi on Gram stain and culture [3, 47]. Some studies on small series of patients with IPN confirmed the results of our systematic review showing that the pathogens usually recognized on bacterial culture were oral commensal bacteria or highly virulent enteric bacteria such as Escherichia coli, Pseudomonas aeruginosa, Klebsiella, or Enterococcus spp, and that, less commonly, patients were found to be infected with multiple pathogens [51].

The radiological findings evocating infection of necrotic collection or bacterial positivity on FNA, as in our series, always represent an indication for intervention [9].

The ON has been originally described by Beger et al., and it has represented, for a long time, the gold standard for the treatment of necrotizing pancreatitis with secondary infection. It consists in a laparotomy through a bilateral subcostal or longitudinal incision, removal of all necrotic tissue, drains insertion, and abdomen closure [52]. Despite its employment for selected cases, in the clinical practice, as demonstrated by this review, this approach is still characterized by high rates of complications (34 to $95 \%)$ and death (11 to $39 \%$ ) and with a risk of long-term pancreatic insufficiency [14]. Husu et al. [27] declare that mortality after ON depends on patient's preoperative risk factors. According to their experience, patients with an average age over 60 years, with preoperative significant comorbidities, necrosectomy within 4 weeks from the clinical onset, and deterioration or prolonged organ failure, apparently seem to report a higher mortality rate. The association of organ failure and IPN with higher mortality rate has also been previously highlighted by Petrov et al. [53], who claimed that the relative risk of mortality doubles when organ failure and 
IPN are both present. This statement is confirmed by this literature review. Indeed, Pascual et al. [38] reported the association between the incidence of perioperative single or multi-organ failure (single 14.3\%; multiple $52.4 \%$ ) and pre-existing significant comorbidities (52.4\%) with a high mortality rate (42.9\% of total cohort's study). Also, Šileikis et al. [30] reported a higher mortality rate (64.1\%) associated with perioperative multi-organ failure rate of $77.3 \%$. Some studies have showed how mortality rate could be negatively influenced by the surgical management within 4 weeks or the low-range time. Indeed, Bausch et al. [41] reported a mortality rate of $63.3 \%$ for patients submitted to $\mathrm{ON}$ with a low average time of 11 days (ranging from 0 to 77). On the other hand, Senthil Kumar et al. [40] report a mortality rate of $6.7 \%$ on a cohort of 15 patients submitted to primary ON for IPN (100\% post-operative positive bacterial culture) with an average time from the onset of malaise and surgery of 31 days (range 17-45).

In the last decade, the growing consent for minimal invasive procedures, also in pancreatic disease, has provided valid alternative strategies to the open approach [8-16]. Less invasive techniques, including ETN, PD, and minimally invasive necrosectomy, are increasingly being used with favourable results.

In 2010, Van Santvoort et al. [14], in their multicentre $\mathrm{RCT}$, showed that the preferred treatment strategy for patients with necrotizing pancreatitis and secondary infection, both from a clinical and an economic point of view, may be considered a minimally invasive step-up approach (PD or endoscopic drainage of the collection) followed, if necessary, by minimally invasive VARD.

This interventional strategy, requiring always a multidisciplinary approach, has been largely discussed in the recent literature. Subsequently, a lot of studies and some RCT trials have systematically compared the endoscopic approach to surgical step-up approach with percutaneous and mini-invasive necrosectomy and/or $\mathrm{ON}$, in order to assess if these minimally invasive approaches were associated with better outcomes in terms of complications, mortality, and length of stay. The PENGUIN trial [54] has compared the endoscopic step-up approach with surgical step-up approach consisting in VARD or laparotomic ones and has showed that the ETN reduced the proinflammatory response and new onset organ failure. The TENSION trial [55] has compared the endoscopic step-up approach (endoscopic ultrasound-guided transluminal drainage followed, if necessary, by endoscopic necrosectomy) with the surgical step-up approach (PD followed, if necessary, by VARD). Despite a not clear superiority of the endoscopic group on the major complication and mortality, they have concluded that the endoscopic step-up approach is probably the treatment to prefer in consideration of the better results for the minor outcomes. Recently, in the MISER trial [56], the outcomes of minimally invasive surgery (laparoscopic or VARD, depending on the location of collection) vs endoscopic transluminal approaches for patients with IPN have been compared showing that the endoscopic approach for IPN significantly reduced major complications, lowered costs, and increased quality of life.

Nevertheless, all these studies are difficult to compare for the variability of patient characteristics and differences between surgical interventions. Indeed, Haney et al. [57] have highlighted differences concerning also drainage techniques, placement of nasocystic catheters, and irrigation of the cyst in the endoscopic procedures among different trials. Moreover, these recommendations do not take into account the large variability in expertise between centres with various techniques but highlighted the importance of an expert pool involvement of specialists composed of gastroenterologist, interventional radiologists, surgeons, and intensive care physicians that may improve the patient outcomes. The whole knowledge of a severe pancreatic disease, usually characterized by severe clinical conditions and hemodynamic instability, allows to perform a correct clinical evaluation and to determine the complete therapeutic approach, also defining the suitable timing for treatment and, eventually, the type of interventional options [8].

\section{Conclusions}

Infected pancreatic necrosis results to be a difficult and challenging disease, hazardous to manage, and often taking advantage in a multidisciplinary approach. In a scientific community who actually prefers the employment of mini-invasive strategies, open necrosectomy is confirmed to be the last resort, useful in selected severe cases, with a defined timing and in case of proven nonfeasibility and no advantage of other minimally invasive approach.

\footnotetext{
Abbreviations

AP: Acute pancreatitis; ANP: Acute necrotic pancreatitis; WON: Walled-off necrosis; IPN: Infected pancreatic necrosis; ON: Open necrosectomy; PD: Percutaneous drainage; ETN: Endoscopic transgastric necrosectomy; VARD: video-assisted retroperitoneal debridement; RCT: Randomized controlled trials; CT: Computed tomography; CRP: C-reactive protein; MRCP: Magnetic resonance cholangiopancreatography; BD: Bile duct; ERCP: Endoscopic retrograde cholangiopancreatography; US: Ultrasonography; OGD: Oesophagogastroduodenoscopy; CTI: CT: Severity index; APACHE II: Acute Physiologic and Chronic Health Evaluation II; ICU: Intensive care unit; ASA: American Society of Anaesthesiologists; FNA: Fine-needle aspiration
}

\section{Acknowledgements}

The authors thank Angela Caporale, Technical Translator and AITI Associate Member, and Dr Francesco Meledandri, Dept. of Humanities, University of Bari, for proof editing this article. 


\section{Authors' contributions}

LIS: study design, collection of data, drafting, tables, figures, and review of literature. AG: drafting and critical revision; AP: drafting, tables, and review of literature; FPP: drafting, review of literature, and critical revision; FC: critical revision; MT: study design, drafting, review of literature, and critical revision. All authors read and approved the final manuscript.

\section{Funding}

The authors declare that they received no funding.

\section{Availability of data and materials}

All data generated or analyzed during this study are included in this published article.

\section{Ethics approval and consent to participate}

Ethics approval and consent were waived because this study is a review of literature with a retrospective case series based on six patients that gave consent to participate for publication.

\section{Consent for publication}

All patients gave consent for publication.

\section{Competing interests}

The authors declare that they have no competing interests.

\section{Author details}

"Unit of General Surgery "V. Bonomo", Department of Biomedical Sciences and Human Oncology, University of Bari "A. Moro", Polyclinic of Bari, Piazza Giulio Cesare, 11, 70124 Bari, Italy. ${ }^{2}$ Department of Emergency and Trauma Surgery, Parma University Hospital, Viale Antonio Gramsci, 14, 43126 Parma, Italy.

\section{Received: 12 June 2020 Accepted: 21 July 2020}

Published online: 29 July 2020

\section{References}

1. Forsmark CE, Vege SS, Wilcox CM. Acute pancreatitis. N Engl J Med. 2016;17; 375(20):1972-1981.

2. Tenner S, Baillie J, DeWitt J, Vege SS, American College of Gastroenterology. American College of Gastroenterology guideline: management of acute pancreatitis [published correction appears in am J Gastroenterol. 2014 Feb; 109(2):302]. Am J Gastroenterol. 2013;108(9):1400-16.

3. Banks PA, Bollen TL, Dervenis C, Gooszen HG, Johnson CD, Sarr MG, et al. Classification of acute pancreatitis--2012: revision of the Atlanta classification and definitions by international consensus. Gut. 2013;62(1):102-11.

4. Sekimoto M, Takada T, Kawarada Y, Hirata K, Mayumi T, Yoshida M, et al. JPN guidelines for the management of acute pancreatitis: epidemiology, etiology, natural history, and outcome predictors in acute pancreatitis. J Hepato-Biliary-Pancreat Surg. 2006;13(1):10-24.

5. Gislason H, Horn A, Hoem D, Andrén-Sandberg A, Imsland AK, Søreide O, et al. Acute pancreatitis in Bergen, Norway. A study on incidence, etiology and severity. Scand J Surg. 2004:93(1):29-33.

6. Lindkvist B, Appelros S, Manjer J, Borgström A. Trends in incidence of acute pancreatitis in a Swedish population: is there really an increase? Clin Gastroenterol Hepatol. 2004;2(9):831-7.

7. Banks PA, Freeman ML. Practice parameters committee of the American College of Gastroenterology. Practice guidelines in acute pancreatitis. Am J Gastroenterol. 2006;101(10):2379-400.

8. Leppäniemi A, Tolonen M, Tarasconi A, Segovia-Lohse H, Gamberini E, Kirkpatrick AW, et al. 2019 WSES guidelines for the management of severe acute pancreatitis. World J Emerg Surg. 2019;14:27.

9. van Santvoort HC, Bakker OJ, Bollen TL, Besselink MG, Ahmed Ali U, Schrijver AM, et al. A conservative and minimally invasive approach to necrotizing pancreatitis improves outcome. Gastroenterology. 2011;141(4):1254-63.

10. Besselink MG, van Santvoort HC, Buskens E, Boermeester MA, van Goor H, Timmerman HM, et al. Probiotic prophylaxis in predicted severe acute pancreatitis: a randomised, double-blind, placebo-controlled trial. Lancet. 2008; 23:371(9613):651-659.

11. Besselink MG, van Santvoort HC, Nieuwenhuijs VB, Boermeester MA, Bollen

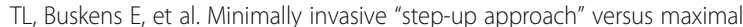
necrosectomy in patients with acute necrotising pancreatitis (PANTER trial): design and rationale of a randomised controlled multicenter trial [ISRC TN13975868]. BMC Surg. 2006; 11:6:6

12. Raraty MG, Halloran CM, Dodd S, Ghaneh P, Connor S, Evans J, et al. Minimal access retroperitoneal pancreatic necrosectomy: improvement in morbidity and mortality with a less invasive approach. Ann Surg. 2010; 251(5):787-93.

13. Rodriguez JR, Razo AO, Targarona J, Thayer SP, Rattner DW, Warshaw AL, et al. Debridement and closed packing for sterile or infected necrotizing pancreatitis: insights into indications and outcomes in 167 patients. Ann Surg. 2008;247(2):294-9.

14. van Santvoort HC, Besselink MG, Bakker OJ, Hofker HS, Boermeester MA Dejong $\mathrm{CH}$, et al. A step-up approach or open necrosectomy for necrotizing pancreatitis. N Engl J Med. 2010; 22;362(16):1491-1502.

15. Arvanitakis M, Dumonceau JM, Albert J, Badaoui A, Bali MA, Barthet M, et al. Endoscopic management of acute necrotizing pancreatitis: European Society of Gastrointestinal Endoscopy (ESGE) evidence-based multidisciplinary quidelines. Endoscopy. 2018:50(5):524-46.

16. Alsfasser G, Hermeneit S, Rau BM, Klar E. Minimally invasive surgery for pancreatic disease - current status. Dig Surg. 2016;33(4):276-83.

17. Ashley SW, Perez A, Pierce EA, Brooks DC, Moore FD Jr, Whang EE, et al. Necrotizing pancreatitis: contemporary analysis of 99 consecutive cases. Ann Surg. 2001;234(4):572-9 discussion 579-80.

18. Tsiotos GG, Luque-de León E, Sarr MG. Long-term outcome of necrotizing pancreatitis treated by necrosectomy. Br J Surg. 1998;85(12):1650-3.

19. Hackert T, Büchler MW. Decision making in necrotizing pancreatitis. Dig Dis. 2016:34(5):517-24

20. Logue JA, Carter CR. Minimally invasive necrosectomy techniques in severe acute pancreatitis: role of percutaneous necrosectomy and video-assisted retroperitoneal debridement. Gastroenterol Res Pract. 2015;2015:693040

21. Bang JY, Holt BA, Hawes RH, Hasan MK, Arnoletti JP, Christein JD, et al. Outcomes after implementing a tailored endoscopic step-up approach to walled-off necrosis in acute pancreatitis. Br J Surg. 2014;101(13):1729-38.

22. Bang JY, Varadarajulu S. Management of walled-off necrosis using the multiple transluminal gateway technique with the hot AXIOS system. Dig Endosc. 2016:28(1):103.

23. Bakker OJ, Issa Y, van Santvoort HC, Besselink MG, Schepers NJ, Bruno MJ, et al. Treatment options for acute pancreatitis. Nat Rev Gastroenterol Hepatol. 2014;11(8):462-9.

24. Seifert H, Biermer M, Schmitt W, Jürgensen C, Will U, Gerlach R, et al. Transluminal endoscopic necrosectomy after acute pancreatitis: a multicentre study with long-term follow-up (the GEPARD study). Gut. 2009; 58(9):1260-6.

25. Testini M, Piccinni G, Lissidini G, Di Venere B, Gurrado A, Poli E, et al. Management of descending duodenal injuries secondary to laparoscopic cholecystectomy. Dig Surg. 2008;25(1):12-5.

26. Lissidini G, Prete FP, Piccinni G, Gurrado A, Giungato S, Prete F, et al. Emergency pancreaticoduodenectomy: when is it needed? A dual nontrauma Centre experience and literature review. Int J Surg. 2015;21(Suppl 1): S83-8.

27. Husu HL, Kuronen JA, Leppäniemi AK, Mentula PJ. Open necrosectomy in acute pancreatitis-obsolete or still useful? World J Emerg Surg. 2020;17;15(1):21.

28. Martinez M, Cole J, Dove J, Blansfield J, Shabahang M, Wild J, et al. Outcomes of endoscopic and surgical pancreatic necrosectomy: a single institution experience. Am Surg. 2019;1;85(9):1017-1024.

29. Cao F, Duan N, Gao C, Li A, Li F. One-step verse step-up laparoscopicassisted Necrosectomy for infected pancreatic necrosis. Dig Surg. 2020;37(3): 211-9.

30. Šileikis A, Pečiulytė E, Misenkienè A, Klimašauskas A, Beiša V, Strupas K. Is minimally invasive surgical treatment justified for severe acute necrotizing pancreatitis patients with dysfunction of two or more organ systems? Wideochir Inne Tech Maloinwazyjne. 2017;12(3):225-30.

31. Wroński M, Cebulski W, Witkowski B, Jankowski M, Kluciński A, Krasnodębski IW, et al. Comparison between minimally invasive and open surgical treatment in necrotizing pancreatitis. J Surg Res. 2017;210:22-31.

32. Rasch S, Phillip V, Reichel S, Rau B, Zapf C, Rosendahl J, et al. Open surgical versus minimal invasive Necrosectomy of the pancreas-a retrospective multicenter analysis of the German pancreatitis study group. PLoS One. 2016;26;11(9):e0163651.

33. Gomatos IP, Halloran CM, Ghaneh P, Raraty MG, Polydoros F, Evans JC, et al. Outcomes from minimal access retroperitoneal and open pancreatic 
necrosectomy in 394 patients with necrotizing pancreatitis. Ann Surg. 2016; 263(5):992-1001.

34. Barreda L, Targarona J, Pando E, Reynel M, Portugal J, Barreda C. Medical versus surgical management for emphysematous pancreatic necrosis: is gas within pancreatic necrosis an absolute indication for surgery? Pancreas. 2015:44(5):808-11.

35. Pupelis G, Fokin V, Zeiza K, Kazaka I, Pereca J, Skuja V, et al. Ultrasoundassisted focused open necrosectomy in the treatment of necrotizing pancreatitis. JOP. 2015;20;16(2):150-158.

36. Tan V, Charachon A, Lescot T, Chafaï N, Le Baleur Y, Delchier JC, et al. Endoscopic transgastric versus surgical necrosectomy in infected pancreatic necrosis. Clin Res Hepatol Gastroenterol. 2014;38(6):770-6.

37. Madenci AL, Michailidou M, Chiou G, Thabet A, Fernández-del Castillo C, Fagenholz PJ. A contemporary series of patients undergoing open debridement for necrotizing pancreatitis. Am J Surg. 2014;208(3):324-31.

38. Pascual I, Sabater L, Añón R, Calvete J, Pacheco G, Muñoz E, et al. Surgical versus nonsurgical treatment of infected pancreatic necrosis: more arguments to change the paradigm. J Gastrointest Surg. 2013;17(9):1627-33.

39. Tu Y, Jiao H, Tan X, Sun L, Zhang W. Laparotomy versus retroperitoneal laparoscopy in debridement and drainage of retroperitoneal infected necrosis in severe acute pancreatitis. Surg Endosc. 2013;27(11):4217-23.

40. Senthil Kumar P, Ravichandran P, Jeswanth $S$. Case matched comparison study of the necrosectomy by retroperitoneal approach with transperitoneal approach for necrotizing pancreatitis in patients with CT severity score of 7 and above. Int J Surg. 2012;10(10):587-92.

41. Bausch D, Wellner U, Kahl S, Kuesters S, Richter-Schrag HJ, Utzolino S, et al. Minimally invasive operations for acute necrotizing pancreatitis: comparison of minimally invasive retroperitoneal necrosectomy with endoscopic transgastric necrosectomy. Surgery. 2012;152(3 Suppl 1):S128-34.

42. Tan J, Tan H, Hu B, Ke C, Ding X, Chen F, et al. Short-term outcomes from a multicenter retrospective study in China comparing laparoscopic and open surgery for the treatment of infected pancreatic necrosis. J Laparoendosc Adv Surg Tech A. 2012;22(1):27-33.

43. Doctor N, Philip S, Gandhi V, Hussain M, Barreto SG. Analysis of the delayed approach to the management of infected pancreatic necrosis. World J Gastroenterol. 2011;21:17(3):366-371.

44. Boland B, Colquhoun S, Menon V, Kim A, Lo S, Nissen NN. Current surgical management of infected pancreatic necrosis. Am Surg. 2010;76(10):1096-9.

45. Bradley EL 3rd. A clinically based classification system for acute pancreatitis. Summary of the international symposium on acute pancreatitis, Atlanta, Ga, September 11 through 13, 1992. Arch Surg. 1993;128(5):586-90

46. Jha AK, Goenka MK, Kumar R, Suchismita A. Endotherapy for pancreatic necrosis: an update. JGH Open. 2018;7;3(1):80-88.

47. van Baal MC, Bollen TL, Bakker OJ, van Goor H, Boermeester MA, Dejong $\mathrm{CH}_{\text {, }}$ et al. The role of routine fine-needle aspiration in the diagnosis of infected necrotizing pancreatitis. Surgery. 2014;155(3):442-8.

48. Working Group IAP/APA Acute Pancreatitis Guidelines. IAP/APA evidencebased guidelines for the management of acute pancreatitis. Pancreatology. 2013:13(4 Suppl 2):e1-15.

49. Thomson JE, Van Dijk SM, Brand M, Van Santvoort HC, Besselink MG Managing infected pancreatic necrosis. Chirurgia (Bucur). 2018;113(3):291-9.

50. van Grinsven J, van Brunschot S, Bakker OJ, Bollen TL, Boermeester MA, Bruno MJ, et al. Diagnostic strategy and timing of intervention in infected necrotizing pancreatitis: an international expert survey and case vignette study. HPB (Oxford). 2016:18(1):49-56.

51. Wroński M, Cebulski W, Pawłowski W, Krasnodębski IW, Słodkowski M. Walled-off necrosis: safety of watchful waiting. Dig Dis Sci. 2015 Apr;60(4): 1081-6.

52. Beger HG, Büchler M, Bittner R, Oettinger W, Block S, Nevalainen T. Necrosectomy and postoperative local lavage in patients with necrotizing pancreatitis: results of a prospective clinical trial. World J Surg. 1988;12(2): 255-62.

53. Petrov MS, Shanbhag S, Chakraborty M, Phillips AR, Windsor JA. Organ failure and infection of pancreatic necrosis as determinants of mortality in patients with acute pancreatitis. Gastroenterology. 2010;139(3):813-20.

54. Bakker OJ, van Santvoort HC, van Brunschot S, Geskus RB, Besselink MG, Bollen $T L$, et al. Endoscopic transgastric vs surgical necrosectomy for infected necrotizing pancreatitis: a randomized trial. JAMA. 2012;14;307(10): 1053-1061.

55. van Brunschot S, van Grinsven J, van Santvoort HC, Bakker OJ, Besselink MG Boermeester MA, et al. Endoscopic or surgical step-up approach for infected necrotising pancreatitis: a multicentre randomised trial. Lancet. 2018;6; 391(10115):51-58

56. Bang JY, Arnoletti JP, Holt BA, Sutton B, Hasan MK, Navaneethan U, et al. An endoscopic transluminal approach, compared with minimally invasive surgery, reduces complications and costs for patients with necrotizing pancreatitis. Gastroenterology. 2019;156(4):1027-1040.e3.

57. Haney CM, Kowalewski KF, Schmidt MW, Koschny R, Felinska EA, Kalkum E, et al. Endoscopic versus surgical treatment for infected necrotizing pancreatitis: a systematic review and meta-analysis of randomized controlled trials. Surg Endosc. 2020;34(6):2429-44.

\section{Publisher's Note}

Springer Nature remains neutral with regard to jurisdictional claims in published maps and institutional affiliations.
Ready to submit your research? Choose BMC and benefit from:

- fast, convenient online submission

- thorough peer review by experienced researchers in your field

- rapid publication on acceptance

- support for research data, including large and complex data types

- gold Open Access which fosters wider collaboration and increased citations

- maximum visibility for your research: over $100 \mathrm{M}$ website views per year

At BMC, research is always in progress.

Learn more biomedcentral.com/submissions 